\title{
COVID-19 y ciudad: hacia un modelo integrado de vivienda, microbiología, ambiente y urbanismo
}

\author{
Felipe Encinas ${ }^{1} \mid$ Katia Soto-Liebe ${ }^{2}$ | Carlos Aguirre-Nuñez ${ }^{3}$ | Bernardo González ${ }^{4}$ | Waldo Bustamante \\ ${ }^{5} \mid$ Alejandra Schueftan ${ }^{6} \mid$ Juan Ugalde ${ }^{7}$ | Carlos Blondel ${ }^{8} \mid$ Ricardo Truffello ${ }^{9} \mid$ Paz Araya ${ }^{10} \mid$ Carmen \\ Freed ${ }^{11}$
}

Recibido: 18-08-2020 | en su versión final: 09-03-2021

Resumen

\begin{abstract}
A partir de mayo de 2020, la crisis sanitaria global causada por el virus SARS-CoV-2 traslada su epicentro hacia Latinoamérica, con foco en ciudades que presentan altos índices de pobreza, segregación y hacinamiento. Los avances en microbiología posibilitan comprender en profundidad las relaciones entre ciudad, COVID-19 y otros microorganismos, pero falta establecer un marco conceptual que las articule, especialmente en contextos donde las determinantes sociales son tan relevantes. Este artículo tiene como objetivo el proponer una aproximación integrada de microbiología, vivienda, ambiente y urbanismo, a partir de un modelo de interacciones y un análisis empírico para Santiago de Chile. En base a esto, se pudo analizar cómo el proceso de propagación en la ciudad se ve potenciada por vulnerabilidades de índole socio espacial, sanitaria intradomiciliaria y urbana, más una aproximación desde el concepto de pobreza energética. Al mismo tiempo, se pudo comprobar como las variables asociadas a estas vulnerabilidades permitían explicar la tasa de incidencia de casos confirmados por cada 100000 habitantes a través de las distintas comunas en el área metropolitana de Santiago de Chile. Dentro de éstas, destacan el nivel de hacinamiento de las viviendas, la cantidad de hogares con jefes/as de hogar en trabajo precario y los viajes hacia el distrito central de negocios de la ciudad. Finalmente, se establece la necesidad de proponer una agenda de investigación para este nuevo equipo multidisciplinario de "Microbioma Urbano" en relación con la necesidad de realización de muestreos microbiológicos que permitan mejorar las condiciones de viviendas, barrios y ciudades, aportando en la superación de las vulnerabilidades identificadas en este estudio.
\end{abstract}

Palabras clave: Coronavirus; vulnerabilidad; pobreza energética; hacinamiento

Citación
Encinas, F. et al. (2021). COVID-19 y ciudad: hacia un modelo integrado de vivienda, microbiología, ambiente y urbanismo. ACE: Architecture, City and Environment, 16(46), 9645. DOI: http://dx.doi.org/10.5821/ace.16.46.9645

\begin{abstract}
1 Doctor en Arquitectura y Urbanismo, Escuela de Arquitectura, Pontificia Universidad Católica de Chile y Centro de Desarrollo Urbano Sustentable (CEDEUS) (ORCiD: 0000-0002-9428-3907, Scopus Author ID: 36809645200), ${ }^{2}$ Doctora en Ciencias Biológicas, Mención Genética Molecular y Microbiología, Facultad de Economía y Negocios, Universidad de Chile (ORCiD: 0000-0002-7021-216X), ${ }^{3}$ Doctor en Gestión Urbana, Escuela de Construcción, Facultad de Arquitectura, Diseño y Construcción, Universidad de Las Américas (ORCiD: 0000-0001-7556-8352), ${ }^{4}$ Doctor en Ciencias Biológicas, Facultad de Ingeniería y Ciencias, Universidad Adolfo Ibañez y Centre of Applied Ecology and Sustainability (CAPES) (ORCiD: 0000-0003-1711-1471), ${ }^{5}$ Doctor en Ciencias Aplicadas, Escuela de Arquitectura, Pontificia Universidad Católica de Chile y Centro de Desarrollo Urbano Sustentable (CEDEUS) (ORCiD: 0000-0002-0420-5383), ${ }^{6}$ Doctora en Ciencias Forestales, Instituto de Arquitectura y Urbanismo, Universidad Austral de Chile e Instituto Forestal, ${ }^{7}$ Doctor en Biología Marina, Centro de Investigación en Tecnologías para la Sociedad (C+), Facultad de Ingeniería, Universidad del Desarrollo y Núcleo Milenio para la Investigación Colaborativa en Resistencia Antimicrobiana (MICROB-R) (ORCiD: 0000-0001-6638-0817, ResearcherID: E-7070-2010), ${ }^{8}$ Doctor en Bioquímica, Instituto de Ciencias Biomédicas, Facultad de Medicina y Facultad de Ciencias de la Vida, Universidad Andrés Bello (ORCiD: 0000-0002-7099-6347, Scopus Author ID: 22936642500, ResearcherID: B-12872010), ${ }^{9}$ Doctor en Ingeniería en Sistemas Complejos, Instituto de Estudios Urbanos y Territoriales, Pontificia Universidad Católica de Chile, Observatorio de Ciudades UC (OCUC), Centro de Desarrollo Urbano Sustentable (CEDEUS) (ORCiD: 0000-0002-6601-9770), ${ }^{10}$ Magíster en Economía Energética, Integrative Research Institute on Transformation of Human-Environment System (IRI THESys), Humboldt-Universität zu Berlin, ${ }^{11}$ Magister en Arquitectura Sustentable y Energía, Escuela de Arquitectura, Pontificia Universidad Católica de Chile. Correo de contacto: felipe.encinas@uc.cl
\end{abstract}




\title{
COVID-19 and City: Towards an Integrated Model of Housing, Microbiology, Environment and Urbanism
}

\begin{abstract}
As of May 2020, the global health crisis caused by the SARS-CoV-2 virus moves its epicentre to Latin America, with cities showing high rates of poverty, segregation, and overcrowding. Current advances in microbiology make it possible to understand in depth the relationships between cities, COVID-19, and other microorganisms, but a conceptual framework to articulate them is lacking, especially in contexts where social determinants are so relevant. This article proposes an integrated approach to microbiology, housing, environment, and urbanism, based on a model of interactions and an empirical analysis applied to Santiago de Chile. It was possible to analyse how the propagation of COVID-19 in the city is enhanced by vulnerabilities of socio-spatial, residential and urban health, including an approach from the concept of energy poverty. At the same time, it was possible to verify how the variables associated with these vulnerabilities allowed to explain the incidence rate per 100000 inhabitants through the different communes of Santiago de Chile. Among these, the level of housing overcrowding, the number of households with heads of household in precarious employment, and travel to the central business district stand out. Finally, the need for microbiological sampling to improve housing conditions, neighbourhoods, and cities propose a new research agenda for this Urban Microbiome" multidisciplinary team, contributing to overcoming the vulnerabilities identified in this research.
\end{abstract}

Keywords: Coronavirus; vulnerability; energy poverty; overcrowding

\section{Introducción}

El virus SARS-CoV-2, causante de la enfermedad llamada COVID-19, irrumpe con fuerza a fines de 2019, propagándose desde Asia a Europa y declarándose pandemia por la OMS el 11 de marzo del 2020. Junto con el cambio de estaciones entre los 2 hemisferios, a partir del mes de mayo, el epicentro de la crisis sanitaria global se ha trasladado a Latinoamérica. De acuerdo con los datos de la Universidad John Hopkins, a fines de julio del 2020, tres países de la región se ubican dentro del top ten con el mayor número de contagios acumulados a nivel mundial: Brasil (2o), Perú (7으) y Chile (8o), con 2.552.265; 400683 y 353.536 casos, respectivamente (John Hopkins University, 2020). En este contexto, desde hace ya tiempo existía la preocupación acerca de las consecuencias de la llegada de SARS-CoV-2 a sectores con altos índices de pobreza, segregación y hacinamiento (Iracheta, 2020), dificultando seriamente medidas tales como el distanciamiento social o la aplicación de cuarentenas extensas (por sus impactos económicos y sociales). Si bien esto nos remite a asentamientos humanos emplazados en ciudades superpobladas como Santiago de Chile, Sao Paulo o Buenos Aires, esto ya se había constatado en sectores vulnerables en países de mayor nivel de desarrollo (Kim y Bostwick, 2020). Por otra parte, algunas de las ciudades con peores índices de calidad del aire a nivel mundial se ubican en Latinoamérica, situación del todo preocupante ya que existe evidencia que apuntaría a la existencia de una relación entre contaminación atmosférica y la dispersión e incidencia del virus y de los impactos de éste en la salud de las personas expuestas a alto niveles de contaminación (Mehmood et al., 2020). Resulta evidente, entonces, que establecer un modelo de análisis que permita vincular la presencia y distribución de SARS-COV-2 con condiciones urbanas, ambientales, habitacionales y sociales permitiría no sólo contribuir al nuevo conocimiento que se genera día a día en torno a COVID-19, sino establecer una agenda de investigación que pueda impactar la toma de decisiones desde la perspectiva sanitaria. 
Sin embargo, estudiar la presencia de SARS-CoV-2 en nuestras viviendas y ciudades, necesariamente nos remite a entender esta relación desde un nuevo paradigma: la existencia de una "ciudad invisible", compuesta por comunidades de microorganismos incluyendo virus como el COVID-19, cohabitando nuestro espacio construido. Hoy en día, existe la capacidad tecnológica para explorar la diversidad taxonómica y funcional de estas comunidades microbianas, a través del conocimiento de la información genética completa en muestras ambientales. Esto es relevante, porque, en términos conceptuales y prácticos, los microorganismos, además de habitar en una gran diversidad de ecosistemas, forman parte permanente y dinámica de todos los macroorganismos, incluyendo al ser humano (Turnbaugh et al., 2007; Zilber-Rosenberg y Rosenberg, 2008). A lo anterior, se debe agregar la consolidación acerca del valor de la biodiversidad de microorganismos a nivel eco sistémico, dado que un ecosistema se comportará mejor y podrá resistir bien diversas perturbaciones mientras más diverso sea en número y abundancia de especies, lo cual representa un elemento clave para establecer también las interacciones entre vivienda, ambiente y ciudad que se discutirán aquí.

El presente artículo tiene como objetivo proponer un modelo integrado de microbiología, vivienda, ambiente y ciudad, para resolver conceptualmente las relaciones que ofrece el binomio COVID-19 y ciudad desde la perspectiva de su propagación y con una mirada situada en Latinoamérica. Este enfoque multidisciplinario es consistente con el artículo fundacional de Martin et al. (2015), que plantea que los estudios sobre ecosistemas microbiológicos se deben situar entre la "ecología evolutiva, antropología, arquitectura y ecología humana”. Sin embargo, hasta el momento no se ha podido establecer una lectura directa desde el diseño arquitectónico y el urbanismo, toda vez que la investigación científica "no está respondiendo las preguntas que son relevantes para la arquitectura", como se declara desde la propia microbiología (Brown et al., 2016).

Hoy en día, resulta evidente como la pandemia de COVID-19 ha detonado estas preguntas, abriendo un amplio campo para la discusión arquitectónica y los estudios urbanos (Ezquiaga Domínguez, 2020; Megahed \& Ghoneim, 2020; Salama, 2020; Sharifi \& Khavarian-Garmsir, 2020). Para llegar a este modelo, se proponen diversas aproximaciones sucesivas a partir de literatura existente y de avances anteriormente publicados, para luego desarrollar las interacciones entre los diversos ámbitos disciplinares que propone este artículo. Luego, en base a este nuevo marco de referencia, se puede analizar de qué manera el proceso de expansión del COVID-19 y otros patógenos respiratorios en la ciudad se ve potenciada por una serie de vulnerabilidades asociadas con la vivienda, el ambiente y la ciudad. Esto se realizó en base a un análisis empírico aplicado inicialmente al área metropolitana de Santiago de Chile, pero proyectable a otras ciudades de Latinoamérica y el mundo. Esta ciudad es significativa como caso de estudio, ya que está altamente segregada en términos socioeconómicos (Link et al., 2015; Sabatini et al., 2001), posee una alta contaminación atmosférica por material particulado (Decreto 67, 2014) y ha sufrido los embates de la pandemia de manera importante, concentrando el $86 \%$ de los casos a nivel nacional (Arroyo et al., 2020). Finalmente, a modo de conclusiones se propone una agenda de investigación para este nuevo equipo multidisciplinario de "Microbioma Urbano" sobre COVID-19, otros microorganismos y ciudad, a la luz de esta discusión.

\section{Hacia un modelo urbano integrado en tiempos de pandemia}

\subsection{Primera aproximación: el rol de la segregación urbana en la pandemia de COVID-19}

La segregación urbana propia de las ciudades latinoamericanas, y en particular la segregación socio residencial, se ve nuevamente interpelada ( $y$ en muchos casos visibilizada) con la pandemia de COVID-19. Si bien la generación de ciudades con mercados liberalizados o de baja regulación claramente agudiza los fenómenos de desigualdad urbana, resulta pertinente entender las raíces de 
estos procesos, particularmente asociado a la producción de viviendas. En ese sentido, la competencia por el espacio, o bid rent — propuesta inicialmente por Alonso (1964) y desarrollada por Shieh (2003) - cuando se basa en los ingresos de las personas, nos presenta su cara más cruda. Es así como al revisar los preceptos asociados a la compra de un bien inmueble, se observa una tensión permanente entre el costo de uso (vale decir, la valoración efectiva de cada uno de los atributos de la vivienda) y el valor de cambio (asociado a la capacidad de pago y endeudamiento por parte del demandante). En el trabajo de Encinas, Truffello, et al. (2019), se plantea que el equilibrio localizacional en una ciudad con baja regulación, genera una segregación por capacidad de pago, y una explotación monopólica de la ubicación que logra capturar todos los beneficios del consumidor en base a un análisis proveniente desde la microeconomía y del modelo de renta de monopolio de Harvey (2005).

En esta lógica, la aproximación metodológica pretende establecer esta tensión, cuyo resultado está relacionado, además, con la segregación y el acceso al espacio urbano, bienes públicos, fuentes laborales de la ciudad, entre otros, generando la denominada vulnerabilidad socioespacial (Figura 1). Esta vulnerabilidad resulta de la exclusión de los bienes de la ciudad dependiendo de la capacidad de pago y deuda de sus habitantes, generando, además, aglomeración y concentración espacial. A nivel nacional, el estudio de Vergara-Perucich, Correa-Parra, et al. (2020) estableció que el precio de la vivienda era la variable que mejor explicaba la propagación de COVID-19 en el área metropolitana de Santiago de Chile, mientras que Bilal et al. (2021) muestra un empeoramiento en las inequidades preexistentes asociadas la mortalidad de la población durante la pandemia, para la misma unidad territorial. Al mismo tiempo, en la literatura internacional de los últimos seis meses es posible observar la relación entre el contagio por COVID-19 y diferentes condiciones urbanas y socioeconómicas, también desde una perspectiva caracterizada fuertemente por la desigualdad. Entre éstas, se pueden mencionar: características demográficas de edad, origen étnico u ocupación para el caso de Estados Unidos (Andersen et al., 2021), la infraestructura de transporte en el distrito urbano de Huangzhon, cercano a Wuhan (Li et al., 2021), la geometría urbana y la ocupación en Hong Kong (Kwok et al., 2021); las condiciones de vivienda y acceso a servicios sanitarios en India (Das et al., 2021); el porcentaje de viviendas bajo condiciones de hacinamiento y la tasa de mortalidad infantil, para las capitales regionales de Brasil (Dayrell et al., 2020) y la densidad poblacional para el caso específico de São Paulo (Nakada \& Urban, 2020); también el hacinamiento (y no la densidad), junto con el tamaño de las viviendas para la ciudad de Nueva York (Hamidi \& Hamidi, 2021); la población mayor de 65 años y finalmente, (en este caso sí) la densidad urbana en Omán (Mansour et al., 2021).

Figura 1. Propuesta conceptual de interacción entre vivienda y ciudad, bajo un contexto de segregación urbana

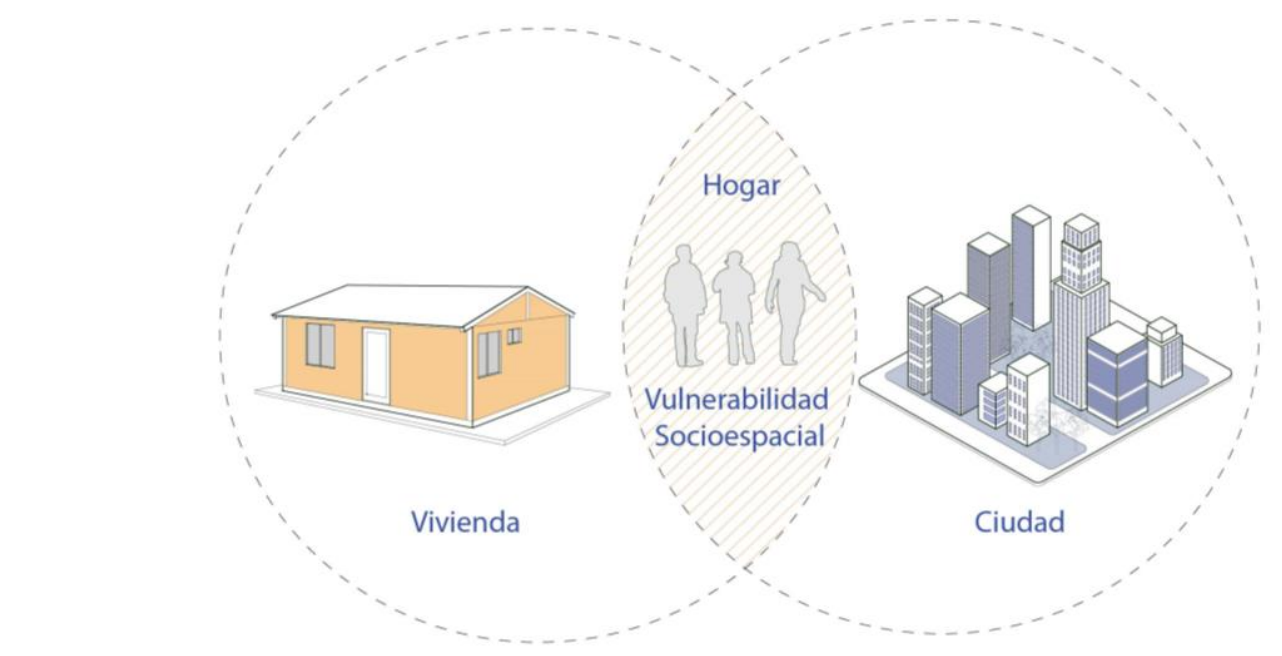

Fuente: Elaboración propia.

ACE, 16 (4.6) CC BY-ND 3.0 ES | UPC Barcelona, España | COVID-19 y ciudad: hacia un modelo integrado de 


\subsection{Segunda aproximación la pobreza energética como modelo de interpretación desde el hogar}

A partir del fenómeno de desregulación urbana establecida en el punto anterior, se ampliará la exploración a la vivienda en sí misma, lo cual puede impactar incluso los elementos técnicos y constructivos de ésta. En este sentido, si el valor de cambio se impone en la decisión de compra de la vivienda, el suelo, y por ende la ubicación, son los elementos de competencia más fuertes. Ante eso, y en ausencia de normativas que regulen fuertemente los aspectos técnicos de la vivienda, éstos sufren el mismo efecto tanto para el desarrollador como para el demandante de vivienda; según el cual el proyecto técnico y el desempeño se convierten en residuales, teniendo un rol secundario en la toma de decisiones. Esta situación hace que la solución de vivienda, y en particular su envolvente térmica, no logre establecer una relación adecuada con su medio ambiente, siendo ineficientes en términos de su intercambio térmico (pérdidas y ganancias de calor), y por ende en su eficiencia energética (Bustamante et al., 2009). Si consideramos que esta situación impacta en mayor grado a la población de sectores de menores ingresos y con dificultades de acceso a bienes y servicios (Encinas, Aguirre, et al., 2019b), estamos en presencia de una vulnerabilidad constructiva-energética, en la intersección de los ámbitos de la vivienda y el medioambiente (Figura 2). Al mismo tiempo, se ha observado que, en ciudades altamente segregadas, como Santiago de Chile, estas zonas vulnerables desde el punto de vista constructivo-energético podrían poseer, además, una mayor amplitud térmica anual, esto es, menores temperaturas en invierno y mayores temperaturas en verano, lo cual se explica, entre otras cosas, por menores espacios de áreas verdes, tanto públicas como privadas (Encinas, Aguirre, et al., 2019a). Esta vulnerabilidad, denominada ambiental en el esquema de la Figura 2 ilustra la relación entre el medio ambiente, la ciudad y el hogar, y que, a raíz de la existencia de ineficiencias en el entorno construido, puede generar, por ejemplo, una mayor exposición a contaminantes como el material particulado y su relación con microorganismos y virus patógenos (como se explicará más adelante).

Figura 2. Propuesta conceptual de interacciones entre vivienda, ciudad y ambiente para una interpretación del concepto de pobreza energética

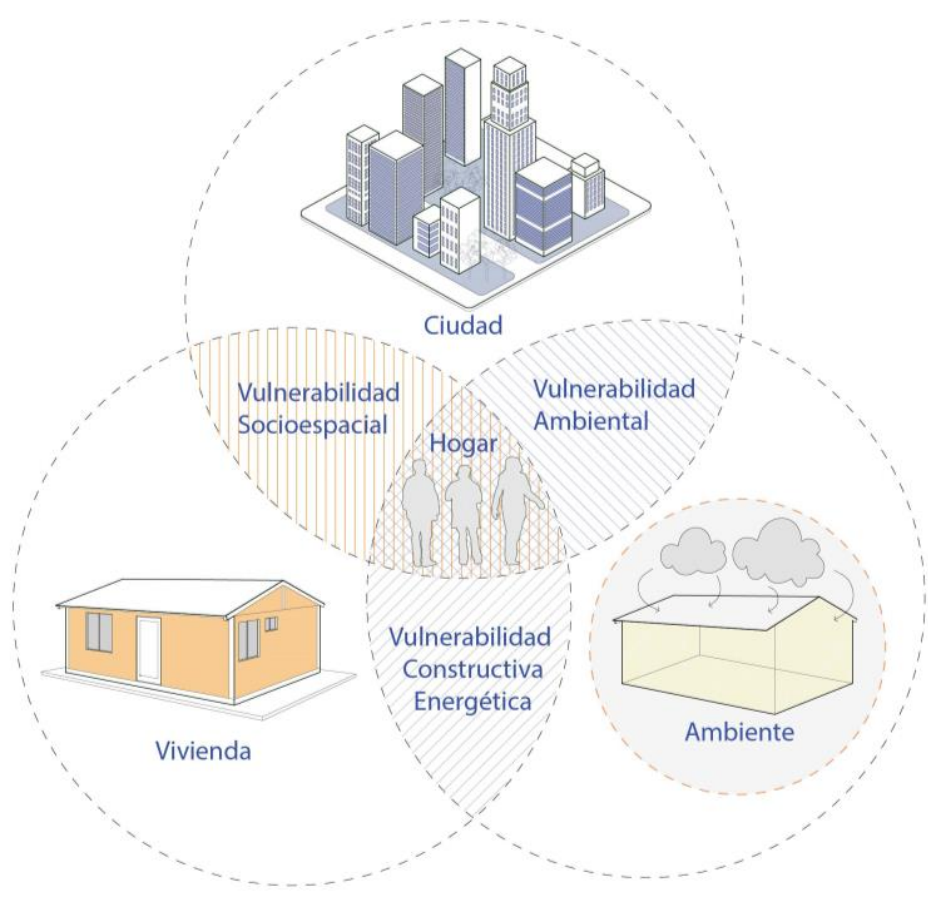

Fuente: Elaboración propia.

ACE, 16 (4.6) CC BY-ND 3.0 ES | UPC Barcelona, España | COVID-19 y ciudad: hacia un modelo integrado de 
En el cruce de estas tres vulnerabilidades (socioespacial, constructiva-energética y ambiental) se propone situar el concepto de pobreza energética. En efecto, la condición de las viviendas antes descrita, lleva a sus habitantes a tener que decidir entre gastar parte importante de sus ingresos en consumo de combustibles para calefacción; reducir sus gastos utilizando combustibles de menor calidad y alta emisión de material particulado; o bien no satisfacer sus necesidades de confort térmico, habitando espacios con bajas temperaturas, incluso bajo lo saludable. En Chile, este fenómeno ha sido observado con particular fuerza en las ciudades del centro-sur y sur del país (asociados a climas fríos y situadas en varias ocasiones entre las más contaminadas del mundo en cuanto a calidad del aire), toda vez que los hogares de ingresos más bajos gastan, en promedio, el porcentaje más alto de su presupuesto familiar en combustibles para calefacción y con frecuencia tienen las temperaturas interiores más bajas (Reyes et al., 2019). En este contexto, la pobreza energética establece un marco de interpretación para la vulnerabilidad de la vivienda, ciudad y su entorno, en el entendimiento que un hogar se encuentra en esta situación cuando no tiene acceso equitativo a servicios energéticos de alta calidad para cubrir sus necesidades fundamentales y básicas, que permitan sostener el desarrollo humano y económico de sus miembros (Calvo et al., 2019).

La pobreza energética al interior de un hogar se relaciona a través de un efecto multiplicador con la propagación del SARS-CoV-2 debido a que la población vulnerable a ambas condiciones coincide, y en tanto hay una mayor tasa de ocupación de las viviendas en la temporada de bajas temperaturas, aumentando la presión sobre la demanda de calefacción. Así, por un lado, en hogares con altos índices de contaminación intradomiciliaria proveniente del uso de leña para calefacción —como es el caso de las ciudades chilenas antes descritas - la mayor exposición a estos contaminantes podría incrementar el riesgo de contagio, tal como ha sido descrito por Mehmood et al. (2020) en su revisión bibliográfica y estudiado por Zhu et al. (2020) para el caso de China. Existe también una fuerte asociación de estas condiciones con la mortalidad por COVID-19, en términos de variables tan específicas como la eficiencia energética de la vivienda (Hu et al., 2021). Por otra parte, los hogares cuyos ingresos no permiten solventar los gastos en calefacción se ven obligados - por las restricciones de movilidad asociadas a la pandemia de COVID-19- a habitar por mayor tiempo espacios de bajo confort térmico, donde incluso la baja temperatura interior convierte a las viviendas en espacios poco saludables. Todas estas condiciones son particularmente sensibles en la población de riesgo, como adultos mayores, población con enfermedades respiratorias crónicas u obesidad; además de la asociación a condiciones sociales, tales como la presencia de mujeres jefas de hogar, migrantes, entre otras (Bouzarovski y Tirado Herrero, 2017; Scarpellini et al., 2015; van der Kroon et al., 2013).

\subsection{Tercera aproximación: modelo integrado para una comprensión multidimensional de la pandemia de COVID-19}

En la condición de pandemia por COVID-19, la vulnerabilidad constructiva-energética, en evolución hacia la pobreza energética, merced de condicionantes ambientales y urbanas, permite establecer algunos elementos de juicio ante el desempeño de las viviendas, en su sentido más amplio. La condición de desempeño térmico, por ejemplo, a través de sus efectos en el ambiente intradomiciliario de los hogares (como son, calidad del aire, temperatura, humedad relativa y problemas de condensación) y en la salud de sus habitantes, entregan elementos para configurar una nueva forma de vulnerabilidad, la sanitaria. Sin embargo, ésta también se puede entender desagregada en función de los ámbitos y escalas en las cuales se materializa; a saber: vulnerabilidad sanitaria socioespacial, vulnerabilidad sanitaria intradomiciliaria y vulnerabilidad sanitaria urbana.

Estas tres vulnerabilidades, más la de pobreza energética antes mencionada, se expresan como la intersección entre los ámbitos de la vivienda, la ciudad y el ambiente (entorno), más una nueva 
dimensión: la microbiológica. En este sentido, el esquema de la Figura 3 nos presenta un modelo integrador con miras a establecer un marco de análisis sistemático, multidisciplinario y centrado en el hogar como unidad central. Sin embargo, dado que el ámbito microbiológico ha sido el menos estudiado en su vínculo con el entorno construido (y menos aún con la vivienda y las condiciones económicas, sociales y culturales que la condicionan), se planteará a continuación establecer un marco conceptual que permita discutir apropiadamente. En otras palabras, entregar luces sobre las preguntas que la microbiología sí podría estar respondiendo a la arquitectura — parafraseando la afirmación de Brown et al. (2016) - a la luz de la literatura existente y de los últimos hallazgos en torno a la pandemia de COVID-19 y otros fenómenos microbiológicos.

Figura 3. Propuesta conceptual de interacciones entre vivienda, ciudad, ambiente y microbiología para una comprensión de la pandemia de COVID-19 desde el hogar

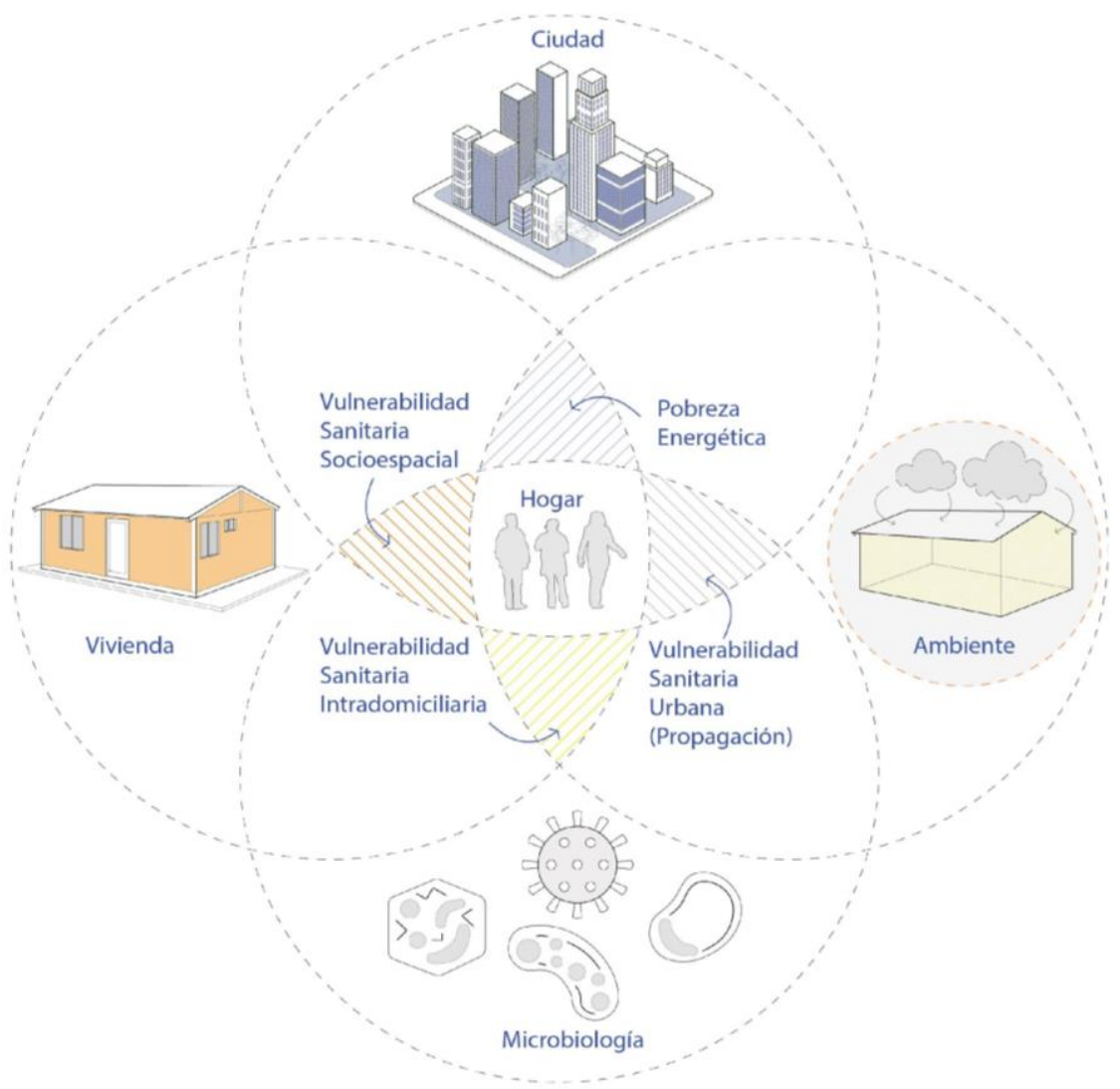

Fuente: Elaboración propia.

\section{Marco conceptual para la incorporación de la dimensión microbiológica}

\subsection{Vulnerabilidad sanitaria socioespacial}

Los microorganismos (bacterias, hongos, protozoos y relacionados) y los virus comparten características similares que son relevantes. Son difíciles de observar, son parte sustantiva y esencial de la vida en el planeta, y una fracción, comparativamente pequeña pero significativa, es capaz de producir patologías infecciosas en el ser humano, transmisibles por distintas vías (aérea, terrestre, alimentos y agua) (Microbiology by Numbers, 2011). Por ejemplo, los virus son capaces de producir, 
entre otras, patologías respiratorias leves y severas, tales como COVID-19 (causada por el coronavirus Sars-Cov-2), y otras como las generadas por el virus de la Influenza, el virus respiratorio sincicial o adenovirus (Zhang et al., 2020). Prácticamente no hay lugares en el planeta en los que los microorganismos estén ausentes, sean ecosistemas terrestres, acuáticos, industrializados, o artificiales. Esto significa que todos los macroorganismos están normal y naturalmente asociados y en contacto con microorganismos, pudiendo ser esta asociación neutra, o potencialmente benéfica o patogénica (Zilber-Rosenberg y Rosenberg, 2008). Entonces, desde la perspectiva de la vulnerabilidad sanitaria socio espacial, debemos considerar que podemos estar expuestos a virus y otros microorganismos patógenos en cualquier lugar, pero la probabilidad o severidad del contagio dependerá de un sinnúmero de factores, varios de los cuales están determinados por las maneras de habitar de los seres humanos en el entorno construido (National Academies of Sciences, 2017).

Esta es una situación que el propio Ministerio de Salud de Chile ha reconocido frente al avance de la pandemia de COVID-19 en los sectores más vulnerables del área metropolitana de Santiago. De acuerdo con éste, las mayores tasas de mortalidad en estas comunas se explicarían por las denominadas "determinantes sociales", entre las que se cuentan "la calidad de la vivienda, la falta de trabajo y la pobreza” (Delgado, 2020). En esta misma línea, la OMS define una serie de grupos vulnerables a COVID-19 y otros patógenos respiratorios, entre los cuales están las personas pobres de zonas urbanas o que habitan viviendas precarias, refugiados y migrantes, personas mayores y/o con factores de riesgo, grupos socialmente marginados y personas en riesgo de violencia interpersonal o daños auto-infringidos a consecuencia de las medidas de distanciamiento físico (OMS, 2020). A partir de lo anterior, se puede inferir que las condicionantes urbanas son fundamentales para la definición de esta vulnerabilidad socioespacial, las cuales serán presentadas en el punto siguiente.

\subsection{Vulnerabilidad sanitaria urbana}

Existe abundante literatura respecto que los individuos viviendo en ecosistemas urbanos presentan una mucho mayor posibilidad de estar expuestos a contagios con patógenos de diversa naturaleza y desarrollar patologías infecciosas, que aquellos que viven en ecosistemas rurales (Gilbert y Stephens, 2018). Esto no debe confundirse con la posibilidad, también diferente, de tener acceso a medidas de protección, control, y manejo de personas infectadas, las que, por cuestiones de infraestructura global y acceso a servicios de salud, entre otros, es mejor en ecosistemas urbanos (National Academies of Sciences, 2017). En este contexto, las alergias han sido relacionadas con la falta de exposición a patógenos durante la infancia, situación característica de ambientes urbanos. Una encuesta realizada en Estados Unidos en los años 2005-2006, mostró que el 45\% de la población infantil era sensible a algún tipo de alérgeno (Flies et al., 2019; Salo et al., 2014). A su vez, las alergias pueden gatillar síntomas en personas que sufren de asma, condición que afecta a 235 millones de personas anualmente y que se encuentra altamente relacionada con la contaminación y al tipo de exposición a microorganismos durante la infancia en ambientes urbanos (Flies et al., 2019; WHO, 2020). Los ecosistemas urbanos, independiente del nivel de desarrollo de los países, se caracterizan por mayores niveles de contaminación (atmosférica, de aguas, manejo de desechos), mayor presión de uso sobre los recursos (alimentación, acceso a agua potable), mayor exposición a fuentes de contagio (por la mayor densidad poblacional relativa y el mayor número de actividades masivas), todos ellos factores que aumentan y explican una mayor vulnerabilidad a infecciones de todo tipo, incluyendo respiratorias como el COVID-19 (King, 2014; Tyakht et al., 2014). En este contexto, medidas tales como las cuarentenas, el distanciamiento físico (social), el uso de mascarillas, el lavado de manos frecuentes, e incluso las medidas de limpieza de superficies reflejan el impacto de las condiciones propias de la vida urbana en los fenómenos de contagio e infección (Cheng et al., 2020; Stephens et al., 2019).

Todos estos aspectos - que se pueden entender en principio desde la escala del individuo y su entorno directo- poseen, sin embargo, fuertes implicancias para el entorno construido, puesto que, 
por ejemplo, el distanciamiento físico va a requerir espacios habitacionales adecuados. Cuando esto no sea posible, por ejemplo, por la presencia de múltiples familias en un espacio común, la OMS indica que las autoridades locales deberán proveer alojamiento temporal y de emergencia para poder realizar cuarentenas efectivas. Esta misma organización va incluso más allá, al indicar que se deberá garantizar "el derecho a la vivienda mediante la suspensión de desalojos, el aplazamiento de pagos de hipotecas y la suspensión de pagos de servicios públicos” (OMS, 2020). Esta consideración, que refiere tanto al ámbito de políticas públicas como de la economía política de la vivienda (VergaraPerucich, Aguirre, et al., 2020), debe entenderse también desde la escala más pequeña, puesto que las características del conjunto de los microorganismos en una vivienda determinarán en gran medida el nivel de adecuación y pertinencia en relación con las medidas sanitarias, abriendo la puerta, además, para su control y remediación, tal como la ventilación o la sanitización. Este aspecto será relevado en el punto siguiente para explicar las consideraciones relativas a la vulnerabilidad sanitaria intradomiciliaria.

\subsection{Vulnerabilidad sanitaria intradomiciliaria}

La exposición a distintos patógenos, incluyendo los respiratorios como el SARS-CoV-2 y otros a nivel domiciliario se ve afectada por diversos factores. En primer lugar, el número de habitantes, sean humanos, mascotas o plagas, donde cada uno de ellos contribuye potencialmente con la presencia de microorganismos, algunos de ellos patógenos. En este sentido, el hacinamiento es especialmente crítico con patógenos respiratorios ya que, dado que la vía de transmisión es principalmente aérea, a mayor número de habitantes por unidad de volumen de aire respirado en común, mayor es el peligro de contagio (Gracey, 2002; Hall et al., 2018). En este contexto, la contaminación del aire a nivel intradomiciliario es un factor significativo a la hora de tener en cuenta posibles contagios con patógenos de transmisión aérea (Gordon et al., 2014), lo cual para el caso chileno ha sido recientemente demostrado (Paredes et al. 2020). En segundo lugar, los hábitos de higiene y los factores culturales asociados, que se traducen en limpieza frecuente de superficies, sitios bien ventilados e iluminados, entre otros, disminuyen la exposición a patógenos virales, bacterianos y fúngicos. Esto es especialmente crítico en los espacios intradomiciliarios con funciones sanitarias, que se utilicen para comer o cocinar, algunos de los cuales son de alta interacción y por ello de alta frecuencia de contagio, en especial de patógenos que son viables en superficies inorgánicas (National Academies of Sciences, 2017). En tercer lugar, el diseño del espacio construido que dice relación con aspectos como exposición a ecosistemas "naturales" (una plaza o parque) provocan aumentos en la biodiversidad de las comunidades microbianas y con ello mayor posibilidad de control de patógenos (Hall et al., 2018); aumento de la luminosidad (disminución de patógenos sensibles a la luz/radiación) y de la ventilación (disminución del número de partículas-vectores de patógenos respiratorios).

Las características de la vivienda, así como su comportamiento y las costumbres de sus usuarios son clave en este punto. De acuerdo a la OECD, en Chile menos del $2 \%$ de las viviendas construidas cumplen con los requisitos térmicos mínimos para su acondicionamiento (2014). En promedio, sobre el $80 \%$ de la población usa algún sistema de calefacción en sus viviendas, cifra que se incrementa al 88\% o más en el sur del país, donde predominan climas con bajas temperaturas (In-Data y CDT, 2019). La demanda de energía para calefacción y la calidad ambiental al interior de las viviendas están fuertemente determinadas por el desempeño térmico de la envolvente, junto a su hermeticidad, soleamiento y las estrategias de ventilación (Bustamante et al., 2009; Schueftan y González, 2015). Al mismo tiempo, la calidad ambiental interior se ve afectada por el tipo de sistema de calefacción y el combustible utilizado. En los tipos de sistemas de calefacción en Chile, predominan los sistemas individuales o estufas (97,3\%). En la Región Metropolitana de Santiago, los combustibles de mayor consumo para calefacción son el gas licuado y el kerosene, los que normalmente se usan en estufas de llama abierta, expulsando los productos de la combustión (humedad, $\mathrm{CO}_{2}$ y otros) hacia el espacio interior. Más hacia el sur del país, el combustible para calefacción es principalmente la leña (con las

ACE, 16 (46) CC BY-ND 3.0 ES | UPC Barcelona, España | COVID-19 y ciudad: hacia un modelo integrado de 9

vivienda, microbiología, ambiente y urbanismo. DOI: http://dx.doi.org/10.5821/ace.16.46.9645 
consecuentes emisiones de material particulado), donde los hogares declaran su uso entre un 88 y 93\% (In-Data y CDT, 2019). Las emisiones de material particulado provenientes del uso de leña y el bajo estándar de desempeño térmico de las viviendas, explican la alta contaminación atmosférica en las ciudades del centro-sur y sur de Chile, las cuales se cuentan entre las mas contaminadas de Latinoamérica (IQ Air, 2020). A esto se suma el alto nivel de infiltraciones de aire en la envolvente (Trebilcock, 2014) y la ausencia de sistemas de ventilación controlada, causando una alta contaminación intradomiciliaria. Esta situación de precariedad térmica en las viviendas aún no se aborda desde la política pública en el área metropolitana de Santiago y solo parcialmente en algunas ciudades del sur del país. Cifras de 2017 del Ministerio de Medio Ambiente señalan que alrededor de 3500 personas murieron prematuramente en el año 2017 por efecto de la contaminación atmosférica de las ciudades en Chile (Chávez, 2019).

La contaminación exterior e interior por PM2.5 (y sus microorganismos asociados) debido al excesivo uso de leña para calefaccionar las viviendas ha sido abordada en diversos estudios que muestran los impactos que esto tiene en los hogares y ciudades, afectando la calidad de vida de la población (Barraza et al., 2016; Jorquera et al., 2018; Schueftan et al., 2016). Por otra parte, la baja calidad térmica de las viviendas conduce a que en un número importante de éstas no se alcancen las temperaturas interiores de confort recomendadas. En el caso chileno, en el segmento socioeconómico en que se encuentran las familias de menores ingresos en el país, con ingreso familiar aproximado entre €360 y €620 al mes, se gasta alrededor de €173 al año en combustibles para calefacción (In-Data y CDT, 2019). Esta situación estaría asociada a la denominada "pobreza energética oculta", en la cual los hogares muchas veces deben renunciar a satisfacer sus necesidades energéticas para poder cubrir otros requerimientos más urgentes, como la alimentación (Castaño-Rosa et al., 2019), y que de acuerdo con RedPE (2017), una parte importante de los hogares de menores ingresos en Chile podrían estar sufriéndola. A esta precariedad se agrega la presencia de fenómenos de condensación en la superficie interior de los sistemas constructivos (producto de su bajo estándar higrotérmico), lo que se acentúa por el alto contenido de humedad (no suficientemente evacuada) producida por algunas tareas domésticas (cocción de alimentos y lavado de ropa), estimulando el crecimiento de variados microorganismos en diferentes partes de la vivienda. Por último, la ya mencionada alta infiltración de aire en la envolvente y los inadecuados métodos y sistemas de ventilación de las viviendas, exponen a los usuarios de la vivienda a los contaminantes exteriores (Barraza et al., 2014; Reyes et al., 2019). El ingreso de material particulado desde el exterior tendría impacto no solo en el contagio y aumento de casos nuevos de COVID-19, sino también en la mortalidad producto de esta enfermedad (Conticini et al., 2020; Travaglio et al., 2021; Wu et al., 2020).

Por otra parte, los grupos más expuestos a las condiciones de vulnerabilidad son los grupos de más bajos ingresos, con viviendas más antiguas y con estándares de calidad más precarios, que no tienen la opción de acceder a combustibles limpios y viven en sectores de mayor densidad de viviendas, donde normalmente se encuentran mayores concentraciones de material particulado (Reyes et al., 2019). Es relevante entender dónde se localizan estos grupos vulnerables, de manera de focalizar estrategias de mejoramiento de viviendas que puedan disminuir los riesgos tanto de contagio como el impacto que éstos puedan tener en la salud de las personas cuando se suman diversos factores de riesgo intradomiciliario.

\subsection{El impacto de la vulnerabilidad en la propagación de la pandemia - Santiago de Chile como caso de estudio}

Una manera de poder observar empíricamente la existencia de vulnerabilidades socioeconómicas, habitacionales y urbanas desde una perspectiva integrada está constituida por la posibilidad de obtener una "supra-variable", que permita reflejar estas múltiples dimensiones a partir de fuentes

ACE, 16 (4.6) CC BY-ND 3.0 ES | UPC Barcelona, España | COVID-19 y ciudad: hacia un modelo integrado de 10 vivienda, microbiología, ambiente y urbanismo. DOI: http://dx.doi.org/10.5821/ace.16.46.9645 
secundarias. Para esto, se utilizará el "Indicador socio material territorial" (ISMT), desarrollado por OCUC (2020), el cual se construye a escala de zona censal a partir de cuatro indicadores socio materiales con especificidad territorial: índice de escolaridad del/de la jefe/a de hogar, índice de calidad material de la vivienda, índice de hacinamiento e índice de allegamiento (CENSO, 2017). Esto da lugar a una variable continua pero que puede ser discretizada para constituir un proxy de la caracterización socioeconómica bajo condiciones de pobreza energética que pretende este artículo (Figura 4).

El caso de Santiago de Chile pone en evidencia, por un lado, la autocorrelación espacial de las variables asociadas al ISMT, y por otro, cómo estas mismas se van aglomerando en el territorio, constituyendo distintas dimensiones de vulnerabilidad, pero que, a fin de cuentas, son diferentes caras de la misma moneda. En este sentido, De Mattos (2002) indicaba el impacto que la transformación neoliberal ha ejercido sobre los mercados de trabajo, configurando una elevada desigualdad y donde se evidencia la concentración de la población de mayores ingresos en "una suerte de triángulo que tiene uno de sus vértices en la comuna de Santiago y luego se despliega hacia el nororiente, cubriendo buena parte de los faldeos cordilleranos, comprendiendo las comunas de Vitacura, Providencia, Las Condes, Lo Barnechea, La Reina y Ñuñoa"; y que otros autores han dado en llamar el "cono de alta renta" de Santiago de Chile (Link et al., 2015).

Si bien a inicios de la pandemia existieron algunos focos iniciales e independientes en el resto del país, la expansión más significativa en esta primera ola nacional se dio en el área metropolitana de Santiago de Chile. Dentro de ésta, la propagación de los contagios de COVID-19 no se dio de manera uniforme o en un sentido neutral a la organización espacial. En efecto, esta siguió un claro patrón espacial desde el centro de la ciudad y las comunas del "cono de alta renta" hacia las periferias. Esto resulta evidente al comparar la distribución de los casos acumulados al 30 de marzo del 2020, al inicio de la pandemia, y al 16 de junio del mismo año1., cuando la enfermedad ya se había propagado masivamente por la ciudad y estaba cerca de encontrar su peak (alrededor de los 6.000 nuevos casos diarios a nivel nacional) (Figura 5).

A la luz de los antecedentes presentados, una de las hipótesis más relevantes para explicar la propagación de COVID-19 en la población está asociada al efecto de las condicionantes espaciales (ciudad y vivienda). Para esto se construyó una base de datos con un total de 24 variables que caracterizarían la vulnerabilidad socio espacial y urbana en los términos propuestos por este artículo (Tabla 1). Se contó, además con datos de transporte público, en registro de tickets, elaborándose una matriz de origen-destino y calculando algunos indicadores de viajes para cada día, desde el 1 de marzo hasta el 15 de mayo. Luego, se exploraron las relaciones entre estos registros y su impacto en las condiciones de contagio de estos por comuna, con un desfase de 15 días, dado el período de incubación de la enfermedad.

Es importante mencionar que no se pudo trabajar con información más desagregada espacialmente en términos de casos nuevos de COVID-19, ya que esta no ha sido puesta a disposición de la comunidad científica. A partir de esta información se buscó, en primer lugar, establecer correlaciones entre las distintas variables de vulnerabilidad con aquellas vinculadas con la propagación de COVID19, expresadas en la tasa de incidencia de casos confirmados por cada 100.000 habitantes, en las comunas que integran el área metropolitana de Santiago de Chile.

\footnotetext{
1 Estas fechas corresponden a los 1aㅡ y 26a informes epidemiológicos, elaborados por el Departamento de Epidemiología del Ministerio de Salud de Chile, respectivamente (MINSAL, 2021).
} 


\section{ACE Architecture, City and Environment}

Figura 4. Indicador socio material territorial (ISMT) discretizado según grupos socioeconómicos predominantes en la zona censal para el área metropolitana de Santiago de Chile

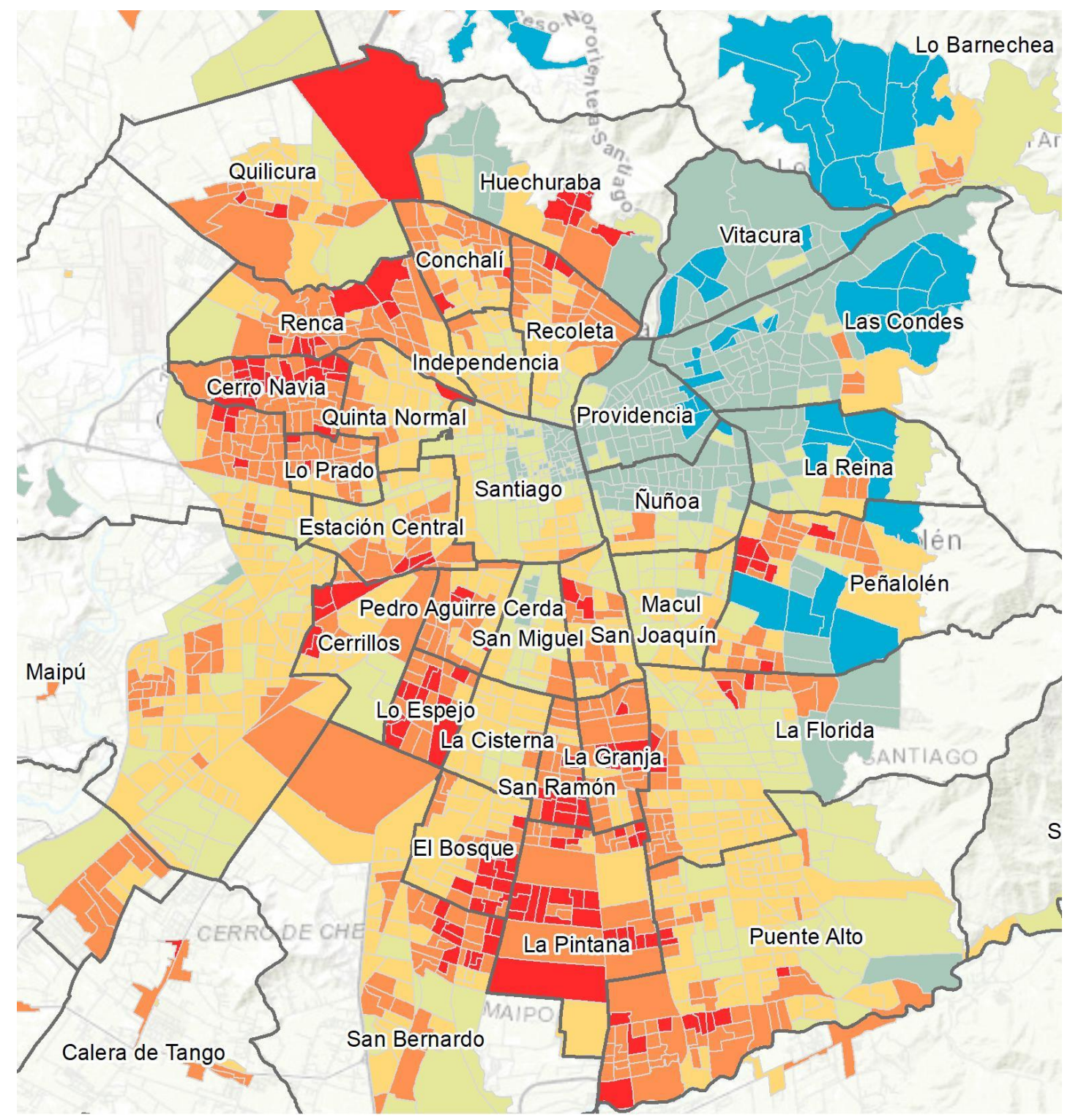

\section{O C U C}

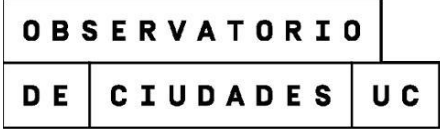

Grupos Socioeconómicos

\begin{tabular}{|l|l|}
\hline Muy Alto \\
\hline Alto \\
\hline Medio Alto \\
\hline Medio \\
\hline Bajo \\
\hline Muy Bajo \\
\hline
\end{tabular}

Fuente del indicador: OCUC

Fuente de datos: INE, 2017

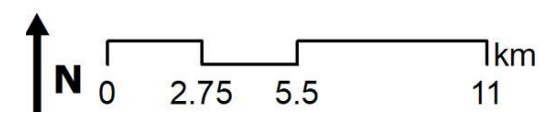


Figura 5. Número de casos acumulados de COVID-19 por comuna en el área metropolitana de Santiago de Chile para el 30 de marzo y el 16 de junio de 2020
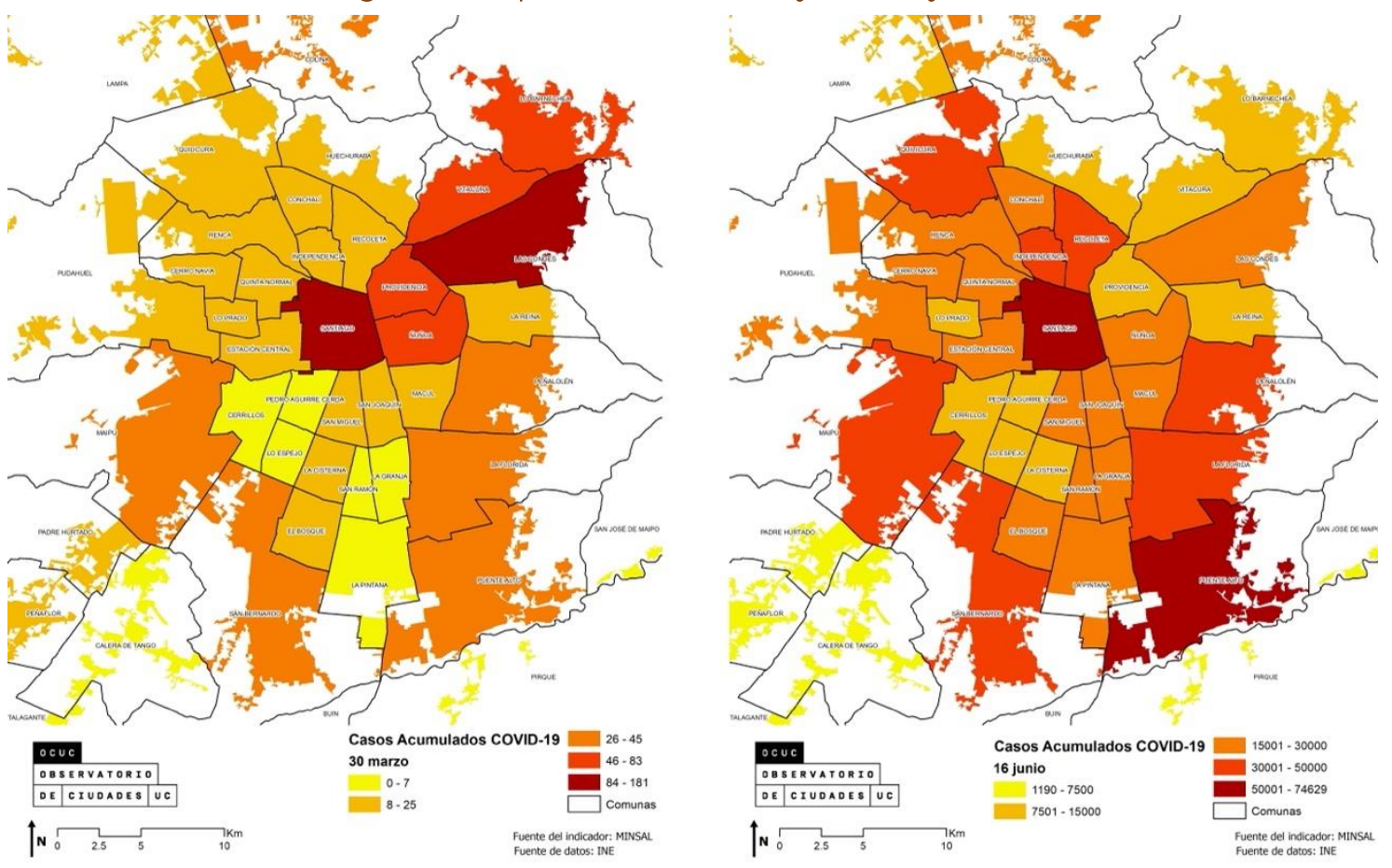

Nota: Izquierda, 30 de marzo de 2020 y derecha, 16 de junio de 2020.

Fuente: Elaboración propia.

Tabla 1. Variables consideradas para el análisis del área metropolitana de Santiago de Chile a nivel de comuna, para el período 30 marzo-16 junio del 2020

\begin{tabular}{|c|c|c|c|c|}
\hline Variable & Mínimo & Máximo & Media & $\begin{array}{c}\text { Desviación } \\
\text { estándar }\end{array}$ \\
\hline Viajes totales hacia la comuna & 3106 & 89221 & 17523 & 17385 \\
\hline Viajes totales desde la comuna & 1161 & 107615 & 17523 & 21239 \\
\hline Viajes internos de la comuna & 277 & 17802 & 3157 & 4249 \\
\hline Viajes que llegan a la comuna & 2814 & 71419 & 14366 & 13779 \\
\hline Viajes que salen de la comuna & 869 & 89813 & 14366 & 17928 \\
\hline Autocontención de viajes* & 0,06 & 0,52 & 0,18 & 0,10 \\
\hline Viajes locales / total de viajes con destino a la comuna & 0,05 & 0,45 & 0,15 & 0,08 \\
\hline Porcentaje de viajes con destino sector oriente & $28,9 \%$ & $65,9 \%$ & $44,6 \%$ & $7,6 \%$ \\
\hline Índice de especialización de destino para comuna de Santiago** & 0,61 & 1,30 & 0,97 & 0,20 \\
\hline Índice de especialización de destino para comuna de Providencia** & 0,52 & 1,32 & 0,96 & 0,20 \\
\hline Índice de especialización de destino para comuna de Las Condes** & 0,31 & 2,34 & 0,95 & 0,42 \\
\hline Diversidad de destinos ${ }^{\star * *}$ & 2,14 & 3,05 & 2,77 & 0,16 \\
\hline Cantidad de viviendas precarias + & 23 & 3723 & 1357 & 897 \\
\hline Porcentaje de viviendas precarias + & $0,08 \%$ & $6,01 \%$ & $2,99 \%$ & $1,6 \%$ \\
\hline
\end{tabular}

ACE, 16 (4.6) CC BY-ND 3.0 ES | UPC Barcelona, España | COVID-19 y ciudad: hacia un modelo integrado de 


\section{ACE Architecture, City and Environment}

\begin{tabular}{|c|c|c|c|c|}
\hline Variable & Mínimo & Máximo & Media & $\begin{array}{c}\text { Desviación } \\
\text { estándar }\end{array}$ \\
\hline Cantidad de viviendas hacinadas ++ & 201 & 14371 & 3950 & 2879 \\
\hline Porcentaje de viviendas hacinadas ++ & $0,72 \%$ & $12,96 \%$ & $7,83 \%$ & $3,46 \%$ \\
\hline Cantidad de hogares allegados & 260 & 9930 & 2055 & 1609 \\
\hline Porcentaje de hogares allegados & $0,93 \%$ & $8,75 \%$ & $4,16 \%$ & $1,99 \%$ \\
\hline Cantidad de hogares con jefe/a de hogar en trabajo precario & 535 & 38478 & 12029 & 8416 \\
\hline Porcentaje de hogares con jefe/a de hogar en trabajo precario & $1,92 \%$ & $46,83 \%$ & $24,83 \%$ & $12,75 \%$ \\
\hline Cantidad de hogares con acceso precario al agua & 22733 & 162324 & 54761 & 39541 \\
\hline Porcentaje de hogares con acceso precario al agua & $0,01 \%$ & $2,46 \%$ & $0,32 \%$ & $0,55 \%$ \\
\hline Tasa de incidencia de casos por cada 100.000 habitantes & 96,72 & 297,90 & 179,27 & 51,99 \\
\hline
\end{tabular}

Notas:

* Corresponde al total de viajes internos de las comunas.

** Corresponde a la especialización territorial de viajeros hacia un destino, vale decir, cuántos viajeros van más a ese destino que a otros.

*** Corresponde a una medida continua, estimada por medio de la fórmula de Shannon (Aguirre \& MarmolejoDuarte, 2011), que refleja la cantidad de trabajadores por destinos en el total del sistema (entre más destinos es mayor el número).

+ Considerando 3 categorías de calidad ("aceptable", "recuperable" e "irrecuperable") asociadas a la evaluación de muros exteriores, techumbre y piso, obteniéndose un índice de vivienda integrado.

++ Definido como la razón entre el número de personas residentes en la vivienda y el número de dormitorios de ésta, determinando categorías de hacinamiento medio (2,5 a 4,9 personas por dormitorio) y hacinamiento crítico (6 y más personas por dormitorio).

Fuentes: CENSO (2017); Ministerio de Ciencia, Tecnología, Conocimiento e Innovación (2020).

Considerando las correlaciones estadísticamente significativas para un 95\% de nivel de confianza, tres variables asociadas a la vulnerabilidad socio espacial aparecen en primer lugar (Figura 6). Vale decir, en la medida en que aumentan las condiciones de hacinamiento de las viviendas, la precariedad de las viviendas (en términos de calidad constructiva) y la cantidad de jefes/as de hogar con trabajo precario, más alta es la tasa de incidencia de la enfermedad a nivel comunal. Esta observación que puede parecer incluso de sentido común no resulta baladí al comprobar la fuerza de la correlación y la magnitud de la asimetría entre las comunas de mayores y menores ingresos, producto de la desigualdad urbana, con extremos de 96,7 y 297,9 en la tasa de incidencia de casos confirmados por cada 100000 habitantes (Tabla 1), para las comunas de La Granja, con predominio de grupos socioeconómicos bajos y ubicada al sur de la ciudad; y Vitacura, en el corazón del cono de alta renta, respectivamente (Figura 4). En el segundo lugar de importancia, pero con correlaciones igualmente significativas, aparecen las variables de vulnerabilidad urbana, asociadas particularmente a condiciones de movilidad dentro de la comuna y en relación con la ciudad en su totalidad. Finalmente, es importante señalar que no se pudo evaluar la correlación con variables de vulnerabilidad intradomiciliaria, dado que la escala en que esta se manifiesta - la vivienda - no es posible de compatibilizar con datos disponibles de contagios por COVID-19 a nivel comunal.

Al relacionar en términos estadísticos, mediante una regresión que explique la tasa de incidencia de casos confirmados por cada 100000 habitantes, se obtiene un modelo donde se conjugan (y sintetizan) factores de las variables de vulnerabilidad anteriormente mencionadas (Tabla 2). Todas estas variables han sido expresadas en términos ponderados (como porcentaje del total), con el objetivo de eliminar el efecto de las unidades (magnitudes) en los coeficientes del modelo. En primer orden de importancia aparecen las condiciones de hacinamiento de los hogares, relevando la importancia que posee la vivienda en la configuración de un hábitat saludable o no saludable. Esto es aún más relevante cuando se conjugan condiciones de pobreza energética, como reflejo de problemáticas sociales complejas y multidimensionales. En segundo lugar, aparece el porcentaje de hogares con jefe/a de hogar en trabajo precario, enfatizando a vulnerabilidad frente a la pandemia producto de las condiciones socioeconómicas de las familias. En tercer lugar, aparecen los viajes que 
Llegan a cada una de las comunas, poniendo en valor la interacción entre las distintas unidades territoriales dentro de un área metropolitana mayor. Esto ciertamente arroja una sombra de duda sobre las denominadas "cuarentenas dinámicas" a escala comunal, estrategia de restricción de movilidad ampliamente utilizada en Chile para el combate a la pandemia. En último lugar aparece el índice de especialización de destino para la comuna de Providencia, toda vez que ésta se localiza dentro del cono de altos ingresos y al mismo genera muchos desplazamientos desde el resto de la ciudad hacia ella, producto de su oferta de fuentes de trabajo. En efecto, pese a que Santiago de Chile muestra ciertos patrones de desarrollo tendientes al poli-centrismo - lo que se refleja en la importancia en estas mismas correlaciones de los viajes al interior de la comuna - sigue mostrando un resabio mono-céntrico (Truffello y Hidalgo, 2015). Luego, el distrito central de negocios se ubicaría justamente en la confluencia de las comunas de Providencia y Las Condes, en el sector conocido popularmente como Sanhattan (Garreton, 2017; Hidalgo et al., 2016). Finalmente, dentro de las cuatro variables independientes seleccionadas para el modelo, las dos mencionadas en primer lugar, estarían asociadas a la vulnerabilidad socio espacial, mientras que las dos restantes, a la vulnerabilidad urbana.

Figura 6. Correlaciones de Pearson (significativas para $p<0,05$ ) entre tasa de incidencia de casos confirmados por cada 100000 habitantes y variables de vulnerabilidad sanitaria socio espacial y urbana

Porcentaje de viviendas hacinadas

Variables de

vulnerabilidad

socioespacial

Porcentaje de viviendas precarias

0,71

Cantidad de hogares con jefe/a de hogar con trabajo precario

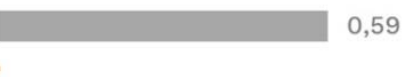

Variables de Viajes locales / total de viajes con destino a la comuna 0,36

vulnerabilidad

urbana

Viajes internos de la comuna

0,35

Fuente: Elaboración propia.

Tabla 2. Regresión lineal múltiple con la tasa de incidencia COVID-19 por 100000 habitantes para el período como variable dependiente e indicadores de vulnerabilidad sanitaria socioespacial y urbana como variables dependientes

Estadísticos de bondad de ajuste del modelo

\begin{tabular}{|c|c|c|c|c|c|c|c|c|}
\hline Variables independientes & $\mathrm{R}^{2}$ & \multicolumn{2}{|c|}{$\mathrm{R}^{2}$ ajustado } & $\begin{array}{l}\text { Cp de } \\
\text { Mallows }\end{array}$ & $\begin{array}{l}\text { AlC de } \\
\text { Akaike }\end{array}$ & \multicolumn{2}{|c|}{$\begin{array}{l}\text { SBC de } \\
\text { Schwarz }\end{array}$} & $\begin{array}{c}\text { PC de } \\
\text { Amemiya }\end{array}$ \\
\hline $\begin{array}{l}\text { [1] Viajes que llegan a la comuna, [2] Índic } \\
\text { de especialización de destino para la } \\
\text { comuna de Providencia, [3] Porcentaje de } \\
\text { viviendas hacinadas, [4] Porcentaje de } \\
\text { hogares con jefe/a de hogar en trabajo } \\
\text { precario }\end{array}$ & 0,659 & \multicolumn{2}{|l|}{0,612} & 1,62 & 397,64 & \multicolumn{2}{|c|}{405,27} & 0,458 \\
\hline \multicolumn{9}{|c|}{ Parámetros del modelo } \\
\hline Variables independientes & Valor & $\begin{array}{c}\text { Error } \\
\text { estándar }\end{array}$ & $\mathrm{t}$ & $\operatorname{Pr}>|t|$ & $\begin{array}{l}\text { Lími } \\
\text { inferior }\end{array}$ & $\begin{array}{l}\text { te } \\
(95 \%)\end{array}$ & Lími & $\begin{array}{l}\text { ite superior } \\
(95 \%)\end{array}$ \\
\hline Intercepción & 716,70 & 214,80 & 3,34 & 0,002 & 277 & & & $1.156,01$ \\
\hline [1] Viajes que llegan a la comuna & $-0,015$ & 0,003 & $-5,05$ & $<0,0001$ & $-0,0$ & & & $-0,009$ \\
\hline $\begin{array}{l}\text { [2] Índice de especialización de destino } \\
\text { para la comuna de Providencia }\end{array}$ & 592,06 & 249,65 & 2,37 & 0,025 & 81,4 & & & 1102,65 \\
\hline [3] Porcentaje de viviendas hacinadas & 17972,22 & 1583,57 & 11,35 & $<0,0001$ & 14.733 & 45 & & 21211,0 \\
\hline $\begin{array}{l}\text { [4] Porcentaje de hogares con jefe/a de } \\
\text { hogar en trabajo precario }\end{array}$ & $-2766,73$ & 558,51 & $-4,95$ & $<0,0001$ & $-390 \varsigma$ &, 00 & & $-1624,46$ \\
\hline
\end{tabular}

Fuente: Elaboración propia. 
En síntesis, el análisis empírico efectuado a partir de los datos recopilados - expresado por medio tanto del análisis de correlaciones, como del modelo de regresión- demuestra el importante rol que diferentes vulnerabilidades asociadas con la vivienda, el ambiente y la ciudad han ejercido en la expansión y distribución del contagio de COVID-19. Si bien ha sido aplicado al caso particular de Santiago de Chile, estos resultados sugieren la validación del modelo de interacciones entre microbiología, vivienda, ambiente y ciudad propuesto para resolver las determinantes sociales y urbanas de la pandemia, al menos para áreas metropolitanas en Latinoamérica.

\section{Conclusiones: nuevas aproximaciones para una agenda de investigación entre COVID-19, otros microorganismos y ciudad}

Los microorganismos en ambientes urbanos han sido estudiados principalmente como agentes causantes de enfermedades, sin embargo, en las últimas dos décadas, el desarrollo de técnicas moleculares de secuenciación ha permitido estudiar la presencia de éstos en el ambiente más allá de su papel como agentes patógenos. En este contexto, han sido caracterizadas las comunidades microbianas de ambientes acuáticos, terrestres y aéreo y se conoce su presencia desde los ambientes polares a los desiertos. En paralelo, también se ha realizado para seres vivos, destacando los avances en el entendimiento de la conformación del de los seres humanos en relación con el medioambiente.

La evidencia muestra que la falta de exposición a cierto tipo de microorganismos y/o a la diversidad que existe en ambientes rurales, afecta la salud de quienes habitan en ambientes urbanos y desafía a incorporar esta dimensión en los estudios medioambientales y en espacios construidos, más aún si consideramos que las personas que habitan espacios urbanos pasan más de un 90\% del tiempo al interior del ambiente construido. Las comunidades microbianas al interior de los espacios construidos es el resultado del ambiente, la vivienda, sus habitantes y los hábitos de éstos, por tanto, conocer su composición, abundancia y distribución requiere integrar esta caracterización con el entorno, trazando los microorganismos desde su origen o fuente, para luego comprender cómo la vivienda, con sus componentes físicos, químicos y biológicos las modifican. La situación sanitaria originada por el virus SARS-COV-2 exige considerar su comportamiento al interior de la vivienda para proponer medidas que permitan evitar o disminuir la probabilidad de contagios intradomiciliarios, con énfasis en las condiciones de vulnerabilidad socio sanitarias que se mencionan en este trabajo.

Desde esta línea de investigación, se ha contemplado estudiar el espacio vivienda y ciudad desde diferentes dimensiones, donde el énfasis se encuentra en el proceso de interacción entre las variables físicas, sociales (hogares), ambientales y biológicas. Estas dimensiones tensionan los elementos de cada una generando vulnerabilidades de índole socio espacial, sanitaria intradomiciliaria y urbana, evidenciándose en el proceso de propagación del COVID-19 en la ciudad, particularmente durante la primera ola de la pandemia en el área metropolitana de Santiago de Chile (de marzo a julio del 2020). En este primer análisis exploratorio, se observa una clara relación entre la tasa de incidencia de casos confirmados en territorios específicos, las condiciones de movilidad, las condiciones de hacinamiento y habitabilidad de la vivienda, validando el enfoque teórico que se plantea inicialmente.

A la luz de este enfoque y los resultados obtenidos, es posible proponer una nueva agenda de investigación para el trabajo futuro de este nuevo equipo multidisciplinario de "Microbioma Urbano". En efecto, esta forma de ver la vivienda y sus sistemas concomitantes (como la ciudad, el barrio y el mundo microbiológico) permite explorar las interacciones y sus influencias en las condiciones de vida y uso de ésta. Esta agenda permitiría establecer mejoras en las condiciones de las viviendas, como también a las de los barrios y ciudades, de forma tal de revisar las actuales condiciones normativas y técnicas de estos elementos, como, por ejemplo, la accesibilidad a la radiación solar directa, las condiciones de ventilación, pérdidas y ganancias de calor, áreas verdes o corredores biológicos.

ACE, 16 (46) CC BY-ND 3.0 ES | UPC Barcelona, España | COVID-19 y ciudad: hacia un modelo integrado de 16 vivienda, microbiología, ambiente y urbanismo. DOI: http://dx.doi.org/10.5821/ace.16.46.9645 
Desde la microbiología son relevantes, por ejemplo, la ventilación que posea la vivienda, la cercanía a corredores biológicos, la contaminación atmosférica, la cantidad y tipo de microorganismos dentro de la vivienda y su interacción con los seres humanos y otros organismos que las habitan. Además, la vivienda, entendida como un sistema, entrega información sobre el impacto en las condiciones de la vida microbiológica, por ejemplo, en términos del tipo y régimen de calefacción. En ese sentido, un plan de muestreo intencionado en lugares de la vivienda (por ejemplo, en los puentes térmicos de su envolvente, superficies interiores o incluso en sus redes de desagüe), permitiendo monitorearlas desde sus condiciones microbiológicas. Además, la propagación de COVID-19 por la ciudad, facilitada por el hacinamiento y otras variables socioeconómicas y urbanas, han puesto de manifiesto la necesidad de repensar los recintos de la vivienda y aportar de mayor forma a disminuir los contagios intradomiciliarios. Por tanto, algunas preguntas que podrían guiar esta agenda futura son: ¿cómo se abordan las vulnerabilidades de tipo socio espacial, sanitaria intradomiciliaria y urbana?, ¿cómo se puede levantar un plan empírico que contribuya a cerrar la brecha de estas vulnerabilidades?, ¿qué relación hay con el territorio físico, biológico o social, particularmente desde la escala intradomiciliaria? Y en especial, se propone el desarrollo de planes de muestreo y seguimiento en entorno construidos, con el objeto de entregar herramientas para el habitar, diseñar y mantener estos espacios en equilibrio con los componentes microbiológicos

\section{Agradecimientos}

Este artículo se ha realizado con financiamiento de la Agencia Nacional de Investigación y Desarrollo (ANID), por medio del proyecto FONDECYT Regular №1201332 “NEXO POBREZA-ENERGÍA-VIVIENDA: Lineamientos de política pública para abordar la pobreza energética desde la relación con la vivienda en áreas metropolitanas". También ha contado con el apoyo del Centro de Desarrollo Urbano Sustentable (CEDEUS), Proyecto ANID/FONDAP №15110020; del Centre of Applied Ecology and Sustainability (CAPES) y del Millennium Initiative for Collaborative Research on Bacterial Resistance (MICROB-R).

\section{Autoría}

Todos los/as autores/as han participado de la escritura del artículo, de acuerdo con las siguientes aproximaciones temáticas: Katia Soto-Liebe, Bernardo González, Juan Ugalde y Carlos Blondel han abordado la dimensión microbiológica; Waldo Bustamante y Carmen Freed, la aproximación físicoconstructiva de la vivienda; Carlos Aguirre, Felipe Encinas y Ricardo Truffello, la perspectiva urbana y geográfica y la aplicación de modelos matemáticos; y finalmente, Alejandra Schueftan y Paz Araya, han trabajado sobre el enfoque de políticas públicas, con énfasis particular en la contaminación del aire y sus impactos en la ciudad.

Conflicto de intereses: Los autores declaran que no hay conflicto de intereses.

\section{Bibliografía}

Aguirre, C. \& Marmolejo-Duarte, C. (2011). Identification of urban subcentres by means of land use, electric consumption and CO2 production. The case of Barcelona Metropolitan Area (RMB). Conference Proceedings of the 27th International Conference on Passive and Low Energy Architecture, PLEA, 125131.

Alonso, W. (1964). Location and Land Use. Toward a general theory of the urban land rent. Harvard University Press.

ACE, 16 (46) CC BY-ND 3.0 ES | UPC Barcelona, España | COVID-19 y ciudad: hacia un modelo integrado de 17 vivienda, microbiología, ambiente y urbanismo. DOI: http://dx.doi.org/10.5821/ace.16.46.9645 
Andersen, L. M.; Harden, S. R.; Sugg, M. M.; Runkle, J. D. \& Lundquist, T. E. (2021). Analyzing the spatial determinants of local Covid-19 transmission in the United States. Science of the Total Environment, 754(January), 142396. DOI: https://doi.org/10.1016/j.scitotenv.2020.142396

Arroyo, C.; Cortés, T.; Engel, E.; Pardow, D. \& Simonetti, P. (20 julio 2020). Informe sobre la evolución de la epidemia de COVID-19 en Chile. Espacio Público. Recuperado de https://www.espaciopublico.cl/ nuestro trabajo/espacio-publico-presenta-reportes-semanales-de-la-evolucion-del-contagio-y-fa llecidos-por-covid-19-chile-y-resto-del-mundo-en-fechas-comparables/

Barraza, F.; Jorquera, H.; Heyer, J.; Palma, W.; Edwards, A. M.; Muñoz, M.; Valdivia, G. \& Montoya, L. D. (2016). Short-term dynamics of indoor and outdoor endotoxin exposure: Case of Santiago, Chile, 2012. Environment International, 92-93, 97-105. DOI: https://doi.org/10.1016/j.envint.2016.03.039

Barraza, F.; Jorquera, H.; Valdivia, G. \& Montoya, L. D. (2014). Indoor PM2.5 in Santiago, Chile, spring 2012: Source apportionment and outdoor contributions. Atmospheric Environment, 94, 692-700. DOI: https://doi.org/10.1016/j.atmosenv.2014.06.014

Bilal, U.; Alfaro, T. \& Vives, A. (2021). COVID-19 and the worsening of health inequities in Santiago, Chile. International Journal of Epidemiology, 1-3. DOI: https://doi.org/10.1093/ije/dyab007

Bouzarovski, S. \& Tirado Herrero, S. (2017). Geographies of injustice: the socio-spatial determinants of energy poverty in Poland, the Czech Republic and Hungary. Post-Communist Economies, 29(1), 27-50. DOI: $\underline{\text { https://doi.org/10.1080/14631377.2016.1242257 }}$

Brown, G. Z.; Kline, J.; Mhuireach, G.; Northcutt, D. \& Stenson, J. (2016). Making microbiology of the built environment relevant to design. Microbiome, 4(1), 6. DOI: https://doi.org/10.1186/s40168-016-0152-7

Bustamante, W.; Rozas, Y.; Cepeda, R.; Encinas, F. \& Martínez, P. (2009). Guía de Diseño para la Eficiencia Energética en la Vivienda Social. Santiago, Chile: Ministerio de Vivienda y Urbanismo, División Técnica de Estudio y Fomento Habitacional; Programa País de Eficiencia Energética y Pontificia Universidad Católica de Chile.

Calvo, R.; Amigo, C.; Billi, M.; Cortés, A.; Mendoza, P.; Tapia, R.; Urquieta, M. A. \& Urquiza, A. (2019). Hacia un indicador territorializado y tridimensional de pobreza energética. Santiago, Chile: Red de Pobreza Energética.

Castaño-Rosa, R.; Solís-Guzmán, J.; Rubio-Bellido, C. \& Marrero, M. (2019). Towards a multipleindicator approach to energy poverty in the European Union: A review. Energy and Buildings, 193, 3648. DOI: https://doi.org/10.1016/J.ENBUILD.2019.03.039

CENSO 2017. (2017). Microdatos Censo 2017. Recuperado de http://www.censo2017.cl/microdatos/

Chávez, M. (11 marzo 2019). Estudio detecta que 3494 personas murieron prematuramente por niveles críticos del aire. El Mercurio.

Cheng, V. C. C.; Wong, S.-C.; Chen, J. H. K.; Yip, C. C. Y.; Chuang, V. W. M.; Tsang, O. T. Y.; Sridhar, S.; Chan, J. F. W.; Ho, P.-L. \& Yuen, K.-Y. (2020). Escalating infection control response to the rapidly evolving epidemiology of the coronavirus disease 2019 (COVID-19) due to SARS-CoV-2 in Hong Kong. Infection Control \& Hospital Epidemiology, 41(5), 493-498. DOI: https://doi.org/10.1017/ice.2020.58

Conticini, E.; Frediani, B. \& Caro, D. (2020). Can atmospheric pollution be considered a co-factor in extremely high level of SARS-CoV-2 lethality in Northern Italy? Environmental Pollution, 261, 114465. DOI: https://doi.org/10.1016/j.envpol.2020.114465

Das, A.; Ghosh, S.; Das, K.; Basu, T.; Dutta, I. \& Das, M. (2021). Living environment matters: Unravelling the spatial clustering of COVID-19 hotspots in Kolkata megacity, India. Sustainable Cities and Society, 65(May 2020), 102577. DOI: https://doi.org/10.1016/j.scs.2020.102577 
Dayrell, A.; Cristina, A.; Andrade, D. S.; Machado, E. L.; Lúcia, A.; Magalhães, A. S.; Ribeiro, P. \& Caiaffa, W. T. (2020). Observando por meio da lupa da COVID-19: um exame das disparidades nas capitais brasileiras. Scielo Preprints. DOI: https://doi.org/10.1590/SciELOPreprints.1411

de Mattos, C. A. (2002). Mercado metropolitano de trabajo y desigualdades sociales en el Gran Santiago: ¿Una ciudad dual? EURE, 28(85). DOI: https://doi.org/10.4067/S0250-71612002008500004

Decreto 67. (2014). Declara zona saturada por material particulado fino respirable MP2,5 como concentración de 24 horas, a la Región Metropolitana. Santiago, Chile: Ministerio de Medio Ambiente. Delgado, F. (30 junio 2020). Determinantes sociales: Gobierno reconoce influencia de dicho factor en muertes por Covid-19. Biobiochile.Cl. Recuperado de: https://www.biobiochile.cl/noticias/ nacional/region-metropolitana/2020/06/30/determinantes-sociales-gobierno-reconoce-influenciadicho-factor-muertes-covid-19.shtml

Encinas, F.; Aguirre, C.; Truffello, R.; Puig, I. \& Hidalgo, R. (2019a). Energy poverty: elements for an interdisciplinary discussion in a developing country. Energy and Society in Transition: 2nd International Conference on Energy Research and Social Science. Tempe, Arizona, EE.UU.

Encinas, F.; Aguirre, C.; Truffello, R.; Puig, I. \& Hidalgo, R. (2019b). Pobreza energética y segregación espacial: nuevas dimensiones urbanas para la desigualdad. 13th International Conference Virtual City and Territory. Barcelona, España. DOI: https://doi.org/10.5821/ctv.8703

Encinas, F.; Truffello, R.; Aguirre, C. \& Hidalgo, R. (2019). Especulación, renta de suelo y ciudad neoliberal. O por qué con el libre mercado no basta. ARQ, 102, 120-133.

DOI: https://doi.org/10.4067/S0717-69962019000200120

Ezquiaga Domínguez, J. M. (2020). Hay que Defender la Ciudad: De la Distopía a la Ciudad Abierta. ACE: Architecture, City and Environment, 15(43), 9518. DOI: http://dx.doi.org/10.5821/ace.15.43.9518

Flies, E. J.; Mavoa, S.; Zosky, G. R.; Mantzioris, E.; Williams, C.; Eri, R.; Brook, B. W. \& Buettel, J. C. (2019). Urban-associated diseases: Candidate diseases, environmental risk factors, and a path forward. Environment International, 133, 105187. DOI: https://doi.org/10.1016/j.envint.2019.105187

Garretón, M. (2017). City profile: Actually existing neoliberalism in Greater Santiago. Cities, 65, 32-50. DOI: https://doi.org/10.1016/j.cities.2017.02.005

Gilbert, J. A. \& Stephens, B. (2018). Microbiology of the built environment. Nature Reviews Microbiology, 16(11), 661-670. DOI: https://doi.org/10.1038/s41579-018-0065-5

Gordon, S. B.; Bruce, N. G.; Grigg, J.; Hibberd, P. L.; Kurmi, O. P.; Lam, K. H.; Mortimer, K.; Asante, K. P.; Balakrishnan, K.; Balmes, J.; Bar-Zeev, N.; Bates, M. N.; Breysse, P. N.; Buist, S.; Chen, Z.; Havens, D.; Jack, D.; Jindal, S.; Kan, H.; ... Martin, W. J. (2014). Respiratory risks from household air pollution in low and middle income countries. The Lancet Respiratory Medicine, 2(10), 823-860. DOI: https://doi.org/10.1016/s2213-2600(14)70168-7

Gracey, M. (2002). Child health in an urbanizing world. Acta Paediatrica, 91(1), 1-8. DOI: https://doi.org/10.1080/080352502753457842

Hall, E. K.; Bernhardt, E. S.; Bier, R. L.; Bradford, M. A.; Boot, C. M.; Cotner, J. B.; del Giorgio, P. A.; Evans, S. E.; Graham, E. B.; Jones, S. E.; Lennon, J. T.; Locey, K. J.; Nemergut, D.; Osborne, B. B.; Rocca, J. D.; Schimel, J. P.; Waldrop, M. P. \& Wallenstein, M. D. (2018). Understanding how microbiomes influence the systems they inhabit. Nature Microbiology, 3(9), 977-982. DOI: https://doi.org/10.1038/s41564-018-0201-z

Hamidi, S. \& Hamidi, I. (2021). Subway Ridership, Crowding, or Population Density: Determinants of COVID-19 Infection Rates in New York City. American Journal of Preventive Medicine. DOI: https://doi.org/10.1016/j.amepre.2020.11.016

Harvey, D. \& Smith, N. (2005). Capital financiero, propiedad inmobiliaria y cultura. Barcelona, España: Universitat Autònoma de Barcelona. 
Hidalgo, R.; De Simone, L.; Santana, D. \& Arenas, F. (2016). Geografías del comercio en Santiago de Chile (1990-2010): de la reestructuración comercial al policentrismo inmobiliario. Revista Geográfica Venezolana, 57(1). Recuperado de: http://erevistas.saber.ula.ve/index.php/regeoven/article/view/11335

Hu, M.; Roberts, J. D.; Azevedo, G. P. \& Milner, D. (2021). The role of built and social environmental factors in Covid-19 transmission: A look at America's capital city. Sustainable Cities and Society, 65(August 2020), 102580. DOI: https://doi.org/10.1016/j.scs.2020.102580

In-Data \& CDT. (2019). Informe final de usos de la energía de los hogares Chile 2018. Santiago, Chile: Corporación de Desarrollo Tecnológico (CDRT) e In-Data Spa.

Iracheta, A. (2020). La ciudad que quisiéramos después de COVID-19. ACE: Architecture, City and Environment, 15(43), 9512. DOI: http://dx.doi.org/10.5821/ace.15.43.9512

IQ Air. (2020). 2019 World Air Quality Report. Region \& City PM2.5 Ranking. Recuperado de: https://www.iqair.com/world-most-polluted-countries

John Hopkins University. (2020). COVID-19 Dashboard by the Center for Systems Science and Engineering (CSSE) at Johns Hopkins University. Coronavirus Resource Center.

Jorquera, H.; Barraza, F.; Heyer, J.; Valdivia, G.; Schiappacasse, L. N. \& Montoya, L. D. (2018). Indoor PM2.5 in an urban zone with heavy wood smoke pollution: The case of Temuco, Chile. Environmental Pollution, 236, 477-487. DOI: https://doi.org/10.1016/i.envpol.2018.01.085

Kim, S. J. \& Bostwick, W. (2020). Social Vulnerability and Racial Inequality in COVID-19 Deaths in Chicago. Health Education \& Behavior, 147(4), 509-513,. https://doi.org/10.1177/1090198120929677

King, G. M. (2014). Urban microbiomes and urban ecology: How do microbes in the built environment affect human sustainability in cities? Journal of Microbiology, 52(9), 721-728. DOI: https://doi.org/10.1007/s12275-014-4364-x

Kwok, C. Y. T.; Wong, M. S.; Chan, K. L.; Kwan, M. P.; Nichol, J. E.; Liu, C. H.; Wong, J. Y. H.; Wai, A. K. C.; Chan, L. W. C.; Xu, Y., Li, H.; Huang, J. \& Kan, Z. (2021). Spatial analysis of the impact of urban geometry and socio-demographic characteristics on COVID-19, a study in Hong Kong. Science of the Total Environment, 764, 144455. DOI: https://doi.org/10.1016/j.scitotenv.2020.144455

Li, B., Peng, Y., He, H., Wang, M., \& Feng, T. (2021). Built environment and early infection of COVID-19 in urban districts: A case study of Huangzhou. Sustainable Cities and Society, 66, 1-10. DOI: https://doi.org/10.1016/j.scs.2020.102685

Link, F.; Valenzuela, F. \& Fuentes, L. (2015). Segregación, estructura y composición social del territorio metropolitano en Santiago de Chile: Complejidades metodológicas en el análisis de la diferenciación social en el espacio. Revista de Geografía Norte Grande, 62, 151-168. DOI: https://doi.org/10.4067/S0718-34022015000300009

Mansour, S.; Al Kindi, A.; Al-Said, A.; Al-Said, A. \& Atkinson, P. (2021). Sociodemographic determinants of COVID-19 incidence rates in Oman: Geospatial modelling using multiscale geographically weighted regression (MGWR). Sustainable Cities and Society, 65, 102627. DOI: https://doi.org/10.1016/j.scs.2020.102627

Martin, L. J.; Adams, R. I.; Bateman, A.; Bik, H. M.; Hawks, J.; Hird, S. M.; Hughes, D.; Kembel, S. W.; Kinney, K.; Kolokotronis, S.-O.; Levy, G.,;McClain, C.; Meadow, J. F.; Medina, R. F.; Mhuireach, G.; Moreau, C. S.; Munshi-South, J.; Nichols, L. M.; Palmer, C.; ... Dunn, R. R. (2015). Evolution of the indoor biome. Trends in Ecology \& Evolution, 30(4), 223-232. DOI: https://doi.org/10.1016/j.tree.2015.02.001

Megahed, N. A. \& Ghoneim, E. M. (2020). Antivirus-built environment: Lessons learned from Covid-19 pandemic. Sustainable Cities and Society, 61, 102350. DOI: https://doi.org/10.1016/j.scs.2020.102350

ACE, 16 (46) CC BY-ND 3.0 ES | UPC Barcelona, España | COVID-19 y ciudad: hacia un modelo integrado de

vivienda, microbiología, ambiente y urbanismo. DOI: http://dx.doi.org/10.5821/ace.16.46.9645 
Mehmood, K.; Saifullah, Iqbal, M. \& Abrar, M. M. (2020). Can exposure to PM2.5 particles increase the incidence of coronavirus disease 2019 (COVID-19)? Science of the Total Environment, 741, 140441. https://doi.org/10.1016/j.scitotenv.2020.140441

Microbiology by numbers. (2011). Nature Reviews Microbiology, 9, 628.
https://doi.org/10.1038/nrmicro2644

Ministerio de Ciencia, Tecnología, Conocimiento e Innovación. (2020). Base de Datos COVID-19. Recuperado de: https://www.minciencia.gob.cl/covid19

Nakada, L. Y. K. \& Urban, R. C. (2020). COVID-19 pandemic: environmental and social factors influencing the spread of SARS-CoV-2 in São Paulo, Brazil. Environmental Science and Pollution Research. DOI: https://doi.org/10.1007/s11356-020-10930-w

National Academies of Sciences. (2017). Microbiomes of the Built Environment: A Research Agenda for Indoor Microbiology, Human Health, and Buildings. National Academies Press. DOI: https://doi.org/10.17226/23647

OCUC. (2020). ISMT. IDE Observatorio de Ciudades UC. Recuperado de https://ideocucocuc.hub.arcgis.com

OECD. (2014). Chile's Pathway to Green Growth: Measuring progress at local level. OECD Local Economic and Employment Development (LEED Programme).

OMS. (2020). Fortalecimiento de la preparación para la covid-19 en las ciudades y otros entornos urbanos: orientaciones provisionales para las autoridades locales. Organización Mundial de la Salud.

Paredes, M., Muñoz, M., Valdés Salgado, M., \& Maldonado, A. (2020). Association between coal and firewood combustion and hospital admissions and mortality in Chile 2015 - An ecological approach. Annals of Agricultural and Environmental Medicine. DOI: https://doi.org/10.26444/aaem/125010

Reyes, R.; Schueftan, A.; Ruiz, C. \& González, A. D. (2019). Controlling air pollution in a context of highenergy poverty levels in southern Chile: Clean air but colder houses? Energy Policy, 124(April 2018), 301-311. DOI: https://doi.org/10.1016/j.enpol.2018.10.022

Sabatini, F.; Cáceres, G. \& Cerda, J. (2001). Segregación residencial en las principales ciudades chilenas: Tendencias de las tres últimas décadas y posibles cursos de acción. EURE, 27(82), 21-42. DOI: https://doi.org/10.4067/S0250-71612001008200002

Salama, A. M. (2020). Coronavirus questions that will not go away: interrogating urban and sociospatial implications of COVID-19 measures. Emerald Open Research, 2, 14. DOI: https://doi.org/10.35241/emeraldopenres.13561.1

Salo, P. M.; Arbes, S. J.; Jaramillo, R.; Calatroni, A.; Weir, C. H.; Sever, M. L.; Hoppin, J. A.; Rose, K. M.; Liu, A. H.; Gergen, P. J.; Mitchell, H. E. \& Zeldin, D. C. (2014). Prevalence of allergic sensitization in the United States: Results from the National Health and Nutrition Examination Survey (NHANES) 20052006. Journal of Allergy and Clinical Immunology, 134(2), 350-359. DOI: https://doi.org/10.1016/j.jaci.2013.12.1071

Scarpellini, S.; Rivera-Torres, P.; Suárez-Perales, I. \& Aranda-Usón, A. (2015). Analysis of energy poverty intensity from the perspective of the regional administration: Empirical evidence from households in southern Europe. Energy Policy, 86, 729-738. DOl: https://doi.org/10.1016/j.enpol.2015.08.009

Schueftan, A. \& González, A. D. (2015). Proposals to enhance thermal efficiency programs and air pollution control in south-central Chile. Energy Policy, 79, 48-57. DOI: https://doi.org/10.1016/i.enpol.2015.01.008

Schueftan, A.; Sommerhoff, J. \& González, A. D. (2016). Firewood demand and energy policy in southcentral Chile. Energy for Sustainable Development, 33, 26-35. DOI: https://doi.org/10.1016/j.esd.2016.04.004 
Sharifi, A., \& Khavarian-Garmsir, A. R. (2020). The COVID-19 pandemic: Impacts on cities and major lessons for urban planning, design, and management. Science of the Total Environment, 749, 1-3. DOI: https://doi.org/10.1016/j.scitotenv.2020.142391

Shieh, Y.-N. (2003). An Early Use of Bid Rent Functions. Urban Studies, 40(4), 791-795. DOI: https://doi.org/10.1080/0042098032000065308

Stephens, B.; Azimi, P.; Thoemmes, M. S.; Heidarinejad, M.; Allen, J. G. \& Gilbert, J. A. (2019). Microbial Exchange via Fomites and Implications for Human Health. Current Pollution Reports, 5(4), 198-213. DOI: https://doi.org/10.1007/s40726-019-00123-6

Travaglio, M.; Yu, Y.; Popovic, R.; Selley, L.; Leal, N. S. \& Martins, L. M. (2021). Links between air pollution and COVID-19 in England. Environmental Pollution, 268, $115859 . \quad$ DOI: https://doi.org/10.1016/i.envpol.2020.115859

Trebilcock, M. (Ed.). (2014). Manual de hermeticidad al aire de edificaciones. Centro de Investigación en Tecnologías de la Construcción (CITEC UBB), Dirección de Extensión en Construcción (DECON UC).

Truffello, R. \& Hidalgo, R. (2015). Policentrismo en el Área Metropolitana de Santiago de Chile: reestructuración comercial, movilidad y tipificación de subcentros. EURE (Santiago), 41(122), 49-73. DOI: https://doi.org/10.4067/S0250-71612015000100003

Turnbaugh, P. J.; Ley, R. E.; Hamady, M.; Fraser-Liggett, C. M.; Knight, R. \& Gordon, J. I. (2007). The Human Microbiome Project. Nature, 449(7164), 804-810. DOI: https://doi.org/10.1038/nature06244

Tyakht, A. V.; Alexeev, D. G.; Popenko, A. S.; Kostryukova, E. S. \& Govorun, V. M. (2014). Rural and urban microbiota. Gut Microbes, 5(3), 351-356. DOI: https://doi.org/10.4161/gmic.28685

Urquiza, A.; Amigo, C.; Billi, M. \& Leal, T. (2017). Análisis de Fuentes Secundarias Disponibles de Alcance Nacional. Pobreza Energética en Chile: ¿un problema invisible? Recuperado de http://redesvid.uchile.cl Lpobreza-energetica/wp-content/uploads/2017/09/Informe-RedPE-septiembre-2017-a.pdf

van der Kroon, B.; Brouwer, R. \& van Beukering, P. J. H. (2013). The energy ladder: Theoretical myth or empirical truth? Results from a meta-analysis. Renewable and Sustainable Energy Reviews, 20, 504.513. DOI: https://doi.org/10.1016/j.rser.2012.11.045

Vergara-Perucich, F.; Aguirre, C.; Encinas, F.; Truffello, R. \& Ladrón de Guevara, F. (2020). Contribución a la economía política de la vivienda en Chile. Santiago, Chile: RiL editores.

Vergara-Perucich, F.; Correa-Parra, J. \& Aguirre-Nuñez, C. (2020). Spatial correlation between COVID19 propagation and vulnerable urban areas in Santiago de Chile. Critical Housing Analysis, 7(2). DOI: https://doi.org/10.13060/23362839.2020.7.2.512

WHO. (2020). Asthma. Fact Sheets. Recuperado de https://www.who.int/news-room/factsheets/detail/asthma

Wu, X., Nethery, R. C., Sabath, B. M., Braun, D., \& Dominici, F. (2020). Exposure to air pollution and COVID-19 mortality in the United States: A nationwide cross-sectional study. MedRxiv. DOI: https://doi.org/10.1101/2020.04.05.20054502

Zhang, N., Wang, L., Deng, X., Liang, R., Su, M., He, C., Hu, L., Su, Y., Ren, J., Yu, F., Du, L., \& Jiang, S. (2020). Recent advances in the detection of respiratory virus infection in humans. Journal of Medical Virology, 92(4), 408-417. DOI: https://doi.org/10.1002/jmv.25674

Zhu, Y., Xie, J., Huang, F., \& Cao, L. (2020). Association between short-term exposure to air pollution and COVID-19 infection: Evidence from China. Science of the Total Environment, 727, 138704. DOI: https://doi.org/10.1016/j.scitotenv.2020.138704

Zilber-Rosenberg, I., \& Rosenberg, E. (2008). Role of microorganisms in the evolution of animals and plants: the hologenome theory of evolution. FEMS Microbiology Reviews, 32(5), 723-735. DOI: https://doi.org/10.1111/j.1574-6976.2008.00123.x 